\title{
Motor Cortex Stimulation for Pain and Movement Disorders
}

\author{
Jeffrey E. Arle and Jay L. Shils \\ Department of Neurosurgery, Lahey Clinic, Burlington, Massachusetts 01805, and Department of Neurosurgery, Tufts University \\ School of Medicine, Boston, Massachusetts 02110
}

\begin{abstract}
Summary: Since initial reports in the early 1990s, stimulation of the M1 region of the cortex (MCS) has been used to treat chronic refractory pain conditions and a variety of movement disorders. A Medline search of literature between 1991 and 2007 revealed 512 cases using MCS. Although most of these relate to the treatment of pain (422), 84 of them involve movement disorders. More recently, several studies have specifically looked at treating Parkinson's disease (PD) with MCS. We
\end{abstract}

report here several of our own cases using MCS to treat poststroke and non-poststroke pain syndromes and movement disorders $(n=8)$, PD $(n=4)$, ET $(n=2)$, and cortico-basal degeneration $(n=1)$. We also cover the essential history of this procedure and our current research using computational modeling to understand further the underlying mechanisms of MCS. Key Words: Motor cortex, cortical stimulation, deep brain stimulation, chronic pain, Parkinson's disease.

\section{INTRODUCTION}

The ground work for using chronic stimulation of the primary motor cortex (MCS) to treat pain and a variety of movement disorders spans over 50 years. Only in the last 5 years, however, have several groups engaged in consistent use of MCS. One does not normally link the treatment of pain per se with the treatment of movement disorders, but this has come to be the case with MCS. Although direct extirpation of M1 was tried by Bucy and others $^{1,2}$ to treat Parkinson's disease (PD) and other disorders, stimulation of regions in the brain on a chronic basis to treat movement disorders began in the 1970s, when Mundinger ${ }^{3}$ tried stimulation of the sensory thalamus to treat spasticity and athetosis changes in five patients. ${ }^{4}$ Removal of the sensory cortex (S1) to treat pain was tried by Penfield and Jasper in a patient with burning pain, but when the pain returned, resection of the precentral gyrus completely ablated the pain. ${ }^{5}$ In 1955 , White and Sweet $^{6}$ demonstrated only $13 \%$ relief with postcentral resection.

As early as 1954, Heath ${ }^{7}$ reported stimulation of the septal area in hopes of activating pleasure centers to alleviate pain. Later, Woolsey et al. ${ }^{8}$ would show inhibition of tremor and rigidity in PD patients by precentral

Address correspondence and reprint requests to: Jeffrey E. Arle, M.D., Ph.D., Department of Neurosurgery, Director, Functional Neurosurgery and Research, Lahey Clinic, Burlington, MA 01805. E-mail: Jeffrey.arle@lahey.org. stimulation, although permanent implantation of electrodes was not tried. In the mid-1980s, Hosobuchi ${ }^{9}$ implanted subcortical electrodes into the somatosensory cortex of 44 chronic pain patients with promising results for leg pain. In 1985 and then 1991, Tsubokawa and colleagues reported chronic stimulation of the M1 region to treat post-thalamic stroke pain. ${ }^{10,11}$ Finally, in 1998, Nguyen et al. ${ }^{12}$ first reported using stimulation of this same region to treat $\mathrm{PD}$, completing the overlap of treatment by using MCS to treat both chronic pain and movement disorders. For the period between 1991 and 2007, a Medline review revealed 512 cases of treatment with MCS, for either pain (422 cases ${ }^{10,13-52}$ ), stroke rehabilitation ( 9 cases $^{13,49,53}$ ), or movement disorders ( 84 cases, 22 of them being mixed MCS and deep brain stimulation [DBS]). ${ }^{12,26,54-64}$ Some of the studies may have included previously reported cases.

At this point, the group with the most experience with MCS is still that of Tsubokawa and Katayama and their group at Nihon University School of Medicine. ${ }^{23-27,59} \mathrm{~A}$ review of their publications indicates a total of 88 patients (some patients apparently are included in multiple reports). They not only explored MCS alone but also compared it to DBS and SCS as separate therapies and in combination. They found that $59 \%$ of patients who underwent DBS or MCS for poststroke involuntary movements had benefit and that $19 \%$ of the patients who underwent MCS primarily for pain control also showed improvement in their movement problems. ${ }^{24}$ For patients 
with phantom limb pain, ${ }^{27}$ the results were somewhat different. Of the five patients with MCS, only one (20\%) demonstrated better pain relief than with either DBS in the ventrocaudal nucleus of the thalamus $(6 / 10$, or $60 \%)$, SCS $(6 / 19$, or $32 \%)$, or a combination thereof. Tsubokawa's initial study in $1991^{10}$ and a follow-up in $1993^{45}$ demonstrated 5 of 11 patients with 'excellent' outcomes (defined as $100 \%$ improvement) at 2 years, compared with 6 of 12 in the first year; however, 3 of 12 patients who were defined as 'good' (60-80\% improvement) at 1 year dropped to either 'fair' (40-60\% improvement) or 'poor' ( $<40 \%$ improvement). These initial results nonetheless helped spur further investigation into MCS for pain. In 1998, Katayama et al. ${ }^{25}$ reported 23 of 31 poststroke patients having satisfactory pain control in initial results; at 2 years, however, pain control was satisfactory in only 8 of the 23 .

There have also been studies placing the electrodes in the subdural space, closer to the direct cortical surface. Three groups have described subdural placement of the MCS electrode. ${ }^{41,47,48}$ From one of these report, there were two hemorrhages among nine patients: one of the two patients died 36 months after implantation and the other patient was left in a persistent vegetative state. ${ }^{41}$

Programming algorithms and parameters for MCS electrodes used to treat chronic pain problems have also varied widely. Reported stimulation amplitudes range from $0.5 \mathrm{~V}$ to $10.5 \mathrm{~V}$, with a mean of $3.8 \pm 2.2 \mathrm{~V}$, and stimulation frequencies range from $5 \mathrm{~Hz}$ to $210 \mathrm{~Hz}$, with a mean of $51.1 \pm 35.7 \mathrm{~Hz}$; pulse width varies from $1 \mu \mathrm{s}$ to $500 \mu \mathrm{s}$, with a mean of $251.2 \pm 141.1$ $\mu$ s. ${ }^{10,12,13,15,17,18,21,23,28-33,35,36,38-49,53,59,61,65}$ The most common adverse effects consisted of short generalized seizures, all of which were caused during the initial testing phases; this was described in fewer than half of the studies. Hardware failures and infection were the second and third most likely complications, respectively. Both Myerson et al. ${ }^{29}$ and Nguyen et al. ${ }^{66}$ reported hematomas, one of which was asymptomatic and the other required surgical intervention.

Several groups in Italy have had a moderate amount of experience using MCS as well. Their work has been focused more on using MCS to treat movement disorders, in particular PD, rather than pain. ${ }^{18,33,54,55,57,60,63}$ Results from these studies were promising in early phases. The Italian Neurosurgical Society study group ${ }^{60}$ reported on a group of 16 patients, with a postsurgical time of 3-30 months for the 10 patients ultimately analyzed. In that study, all but 1 of the 16 patients were ineligible for DBS because of age, MRI findings, or psychological problems. The mean length of disease of the study population was 12.4 years. Of the 10 patients in the analysis, 3 had $<25 \%$ improvement on a global rating scale, 6 had $25-50 \%$ improvement, and 1 had $>50 \%$ improvement after MCS. The stimulation param- eters $2.5-6 \mathrm{~V}, 150-180 \mu \mathrm{s}$, and $25-40 \mathrm{~Hz}$ (although the trial range was larger).

At a presentation by this group at the 2005 World Society for Stereotactic and Functional Neurosurgery meeting in Rome, ${ }^{67}$ the Italian Neurological Society study group reported an improvement (decrease in scores) in the UPDRS III at the 3-and 6-month time periods, with a trend back to baseline thereafter. At another international meeting in New York in 2006, data were presented on patients up to 24 months after implantation. ${ }^{68} \mathrm{~A}$ similar trend on the UPDRS III was seen with a statistically significant improvement at 1,3 , and 6 months, with a trend back to baseline between 6 and 12 months; after 12 months, however, there again appeared to be some improvement.

The M1 region of the cortex is in some sense the final common link between deeper circuitry coordinating movement and the spinal cord itself. It is one of the few areas in which the pyramidal and extrapyramidal systems interact. Disorders of movement, such as PD, tremor, or dystonia, may therefore respond to some type of stimulation of cells in this region, particularly in light of the suggestive clinical precedents noted here. Moreover, the cortex is likely to be integral in the perception of pain per se, because complete lesioning of pathways in the periphery and spinal cord can still leave the patient sensing pain as if from those very areas. Even a stroke in the thalamus creates the sense of pain in one or more areas damaged by the stroke, despite there being no injury more distal in the nervous system. Electrically modulating the cortex may thus be able to exert a beneficial outcome for patients with such pain.

Extradural MCS has advantages over DBS in that it can be performed without the need for general anesthesia, does not require stereotactic techniques or frame, does not require microelectrode recordings, and in theory virtually eliminates the possibility of creating a hemorrhage. It is therefore important to consider MCS as an alternative or even preliminary procedure to DBS in some cases. In particular, it should be considered in PD, as well as in chronic severe refractory pain syndromes in the face or upper extremity, which are coded by regions within M1 on the more accessible lateral convexity surface of the cortex.

\section{METHODS}

\section{Surgical and cortical mapping technique}

Although surgical access to the M1 region can be obtained by means of only a single burr hole, we prefer to make a small craniotomy opening. The midpoint from nasion to inion is determined and an opening centered over a line from $\sim 1 \mathrm{~cm}$ behind this midpoint toward the anterior margin of the tragus is made using a curved scalp incision. In this way, exposure for a craniotomy 


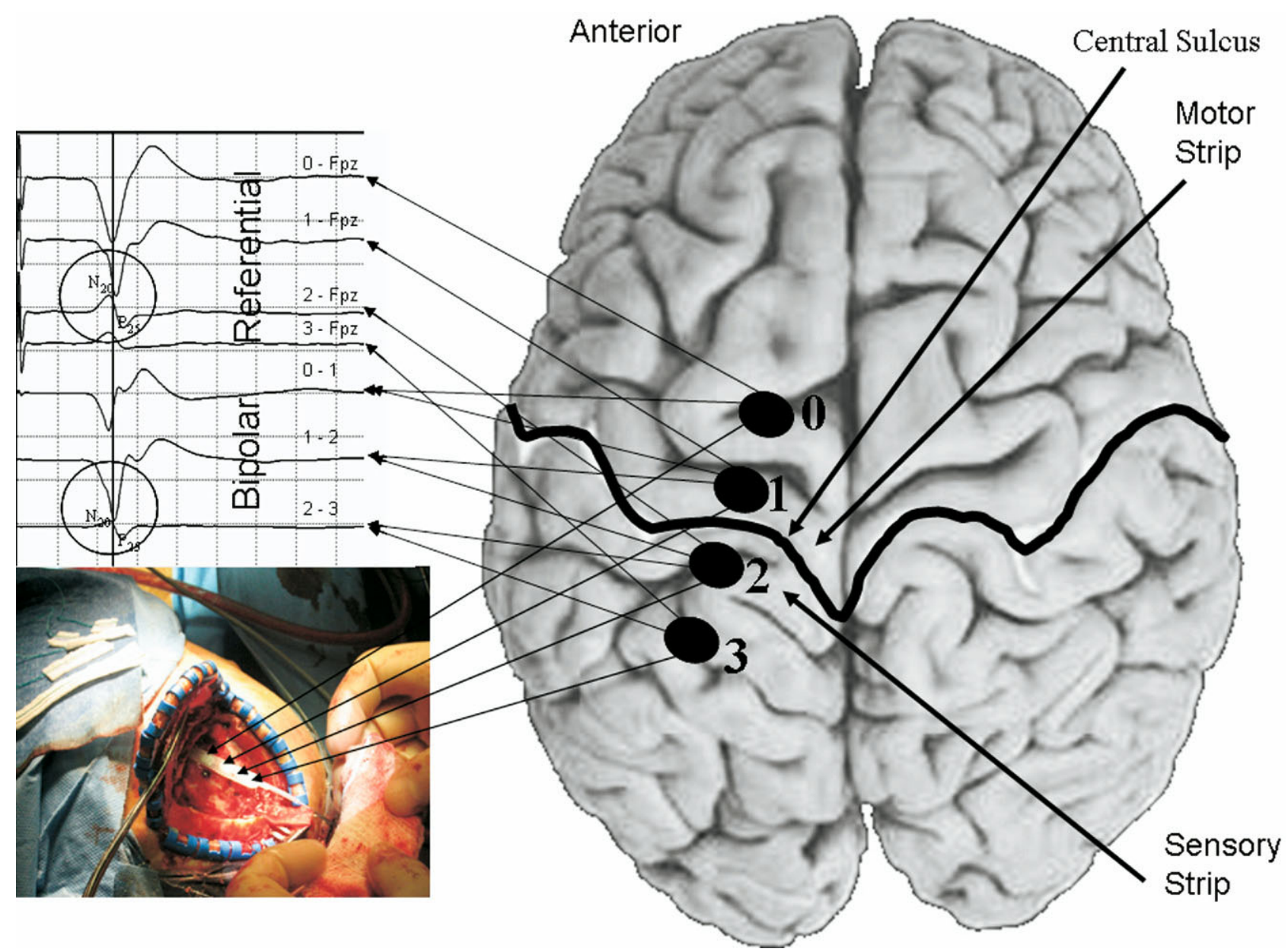

FIG. 1. Use of the somatosensory evoked potentials (SSEP) reversal potential method to determine location of M1 extradurally. Contacts $0-3$ of a typical four-contact paddle-type electrode are shown, in this example with placement across the underlying central sulcus. The waveforms at the upper left show the SSEP in each contact. The reversal of phase occurs, in this example, between contacts 1 and 2. The inset at the lower left is the intraoperative photo of this technique in use, revealing the relative size of the lead and the craniotomy opening. By moving the lead around in different locations, the path of the sulcus can be mapped out on the dura.

that measures roughly $5-6 \mathrm{~cm}$ in diameter is made and can be adjusted slightly superiorly or inferiorly along the convexity to map face or hand as desired. Typically, a cerebellar retractor is the only instrument necessary to maintain the opening during the procedure. We do not use a Mayfield head holder, because the head does not need to be rigidly held in place, which eliminates the risk of further injury if a patient has a seizure induced by mapping.

Both somatosensory and motor mapping can be used intraoperatively to determine the course of the central sulcus and the M1 region underlying the dura. We use both methods in each case, for internal corroboration. Somatosensory testing consists of placing the four-contact Resume lead (Medtronic, Minneapolis, MN) on the dura in a variety of directions, mostly perpendicular to the suspected precentral gyrus. Median and ulnar nerve somatosensory evoked potentials (SSEPs) are then run using a $20 \mathrm{~mA}-100 \mu$ s monopolar square pulse at a rate of $4.32 \mathrm{~Hz}$. SSEPs are recorded from the Resume lead in both a bipolar (contact $0-1,1-2,2-3$ ) and a monopolar (all referenced to the 10-20 location of Fpz) recording montage. The central sulcus is determined as the point at which the N20 response phase reverses (FIG. 1). This process is performed in multiple locations, to map out the central sulcus over the complete craniotomy opening, and short regions just under the bone opening if needed.

Motor mapping consists of placing an anodal 5-mm stimulation ball probe (Model E1564; Valleylab, Gosport, UK) on the dura over the M1 area referenced to a cathode placed at Fpz. Stimulation consists of trains of five stimuli each, at a rate of five trains per second, a $500-\mu$ s pulse width, and a 4-ms interspike interval. Stimulation amplitudes are slowly increased at each location starting at $5 \mathrm{~mA}$ and increasing to a maximum of $25 \mathrm{~mA}$. Stimulation can then be stopped when the first electromyographic (EMG) response is noted.

EMG needles are placed in bipolar fashion (separated by $2 \mathrm{~cm}$ ) in the orbicularis oculi, orbicularis oris, trapezius, deltoid, biceps, triceps, flexor carpi ulnaris, abduc- 


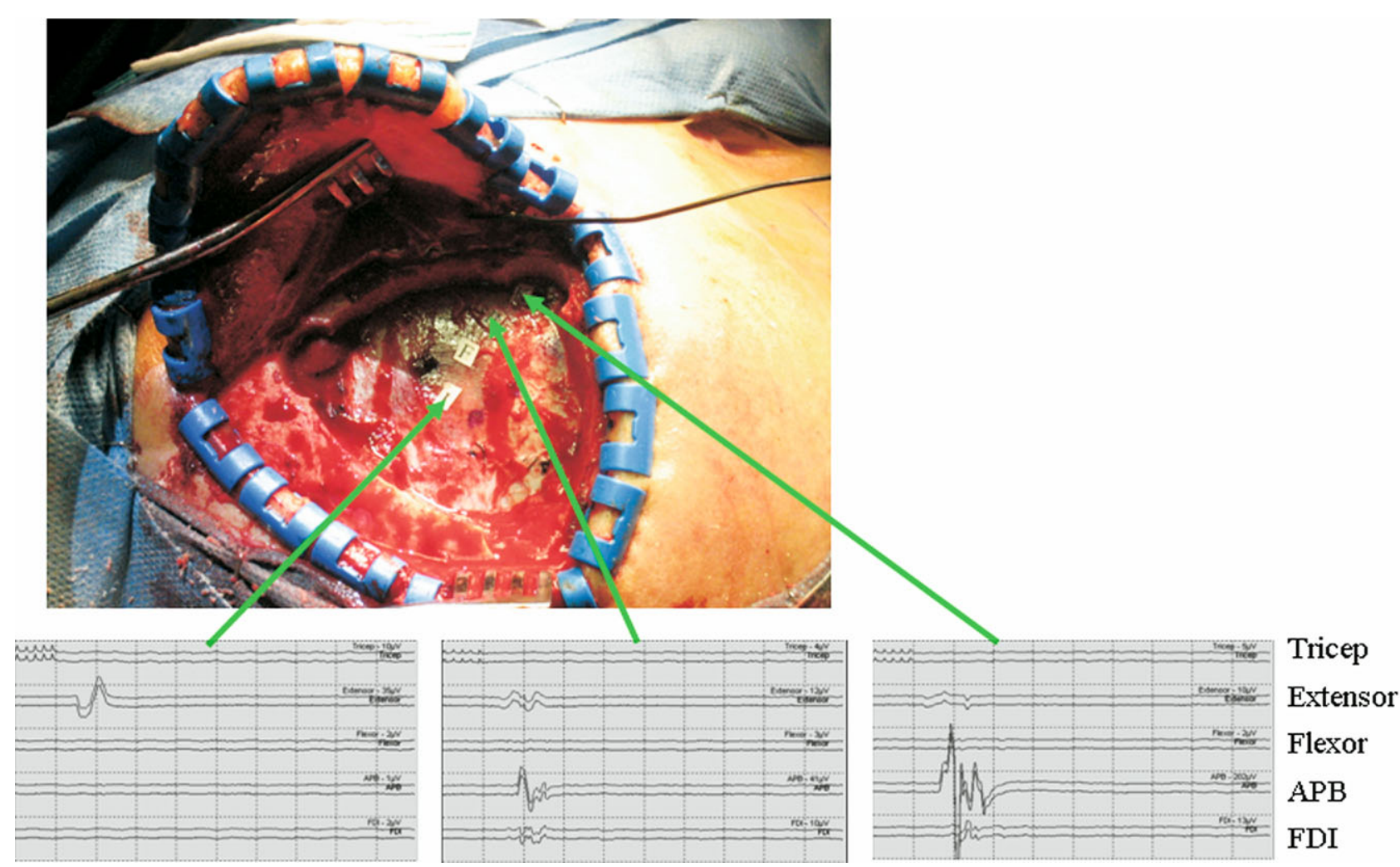

FIG. 2. Use of the cortical mapping technique for determining location of M1 regions. Three electromyograms (EMG) from muscles in the upper extremity are shown, after stimulation with a ball-tip electrode in three locations on the dura. The EMG at the far left shows activation of the extensor muscle in the forearm; the other two show activation of the abductor pollicis brevis muscle in the hand. This technique corroborates the SSEP method (FIG. 1) and helps determine more precisely the underlying thresholds for individual muscle groups.

tor pollicis brevis, first dorsal interosseous, quadriceps, tibialis anterior, and abductor hallucis muscles. Stimulation is performed with a Grass S-88 and two SIU-7 constant current stimulus isolators (Astromed-Grass, West Warwick, RI). Responses are recorded on a Cascade neurological monitoring system (Cadwell, Kennewick, WA). Figure 2 shows an example of the findings in the extensor and abductor pollicis brevis muscles with this technique. In this fashion, two independent types of intraoperative physiology may be used in locating the precentral gyrus.

Critical for the ability to obtain these neurophysiological data is the accompanying anesthetic technique. We use a complete TIVA (total intravenous anesthetic) protocol, with a continuous dose of propofol combined with either fentanyl or remifentanil. Standard doses are in the range of $75-150 \mu \mathrm{g} / \mathrm{kg} / \mathrm{min}$ for propofol and $0.05-0.5$ $\mu \mathrm{g} / \mathrm{kg} / \mathrm{min}$ of fentanyl or remifentanil. No nitrous inhalational agent is used and no muscle relaxants are used.

Patient programming is typically begun within $24 \mathrm{~h}$ of electrode implantation. At the initial programming session, all contacts are checked in a monopolar setting using $210 \mu \mathrm{s}$ and $130 \mathrm{~Hz}$. The voltage is slowly raised to $4.0 \mathrm{~V}$, to look for adverse motor movements and sensory changes. As amplitude is slowly raised, the patient state is evaluated. One primary concern is the possible generation of seizure activity during these tests. To date, we have had two seizures generated during the programming phase. In one patient, a focal motor seizure may have occurred 2 days after initial programming; it was not witnessed by medical personnel, but the description fit well with this type of seizure. This was a patient in whom a seizure was generated during M1 mapping in the operating room. Since then, all our MCS patients in whom a seizure occurred during intraoperative mapping are kept at $<2.5 \mathrm{~V}$ for the first 2 weeks after surgery. We do not prescribe antiepileptic medications, however. At 18month follow-up in 1 poststroke pain patient, a seizure was generated while the stimulator voltage was being raised from $4.0 \mathrm{~V}$ to $4.3 \mathrm{~V}$. The patient's voltage has since been kept below $4.0 \mathrm{~V}$, and no further seizure activity has been noted.

In our four PD patients, contacts 1 and 2 were left on, with the stimulator amplitude at $3.0 \mathrm{~V}$, assuming the patient was able to tolerate each of these settings. If a patient felt unable to tolerate these settings, for any reason, then either contact 3 or 0 alone was used instead. In all cases, it was possible to activate two contacts at the initial programming session.

The use of cathodal stimulation may seem odd, given 
TABLE 1. Motor Cortex Stimulation (MCS) Settings at Last Follow-Up Visit

\begin{tabular}{|c|c|c|c|c|c|c|c|c|c|c|c|c|c|c|c|c|c|}
\hline \multirow[b]{3}{*}{ Patient } & \multirow{3}{*}{$\begin{array}{c}\text { Time } \\
\text { Since } \\
\text { Surgery, } \\
\text { mo }\end{array}$} & \multicolumn{8}{|c|}{ Left Hemisphere } & \multicolumn{8}{|c|}{ Right Hemisphere } \\
\hline & & \multirow{2}{*}{$\begin{array}{l}\text { Amplitude, } \\
\mathrm{V}\end{array}$} & \multirow{2}{*}{$\begin{array}{c}\text { Pulse } \\
\text { Width, } \\
\mu \mathrm{s}\end{array}$} & \multirow{2}{*}{$\begin{array}{l}\text { Frequency, } \\
\mathrm{Hz}\end{array}$} & \multicolumn{4}{|c|}{ Contacts } & \multirow[b]{2}{*}{ Case } & \multirow{2}{*}{$\begin{array}{l}\text { Amplitude, } \\
\text { V }\end{array}$} & \multirow{2}{*}{$\begin{array}{c}\text { Pulse } \\
\text { Width, } \\
\mu \mathrm{s}\end{array}$} & \multirow{2}{*}{$\begin{array}{c}\text { Frequency, } \\
\mathrm{Hz}\end{array}$} & \multicolumn{4}{|c|}{ Contacts } & \multirow[b]{2}{*}{ Case } \\
\hline & & & & & 0 & 1 & 2 & 3 & & & & & 0 & 1 & 2 & 3 & \\
\hline MCS1 & $18,6^{*}$ & 3.2 & 240 & 130 & - & - & - & $\mathrm{n} / \mathrm{a}$ & + & - & - & - & - & - & - & 一 & - \\
\hline MCS2 & 12 & 3.5 & 210 & 130 & - & - & + & + & $\mathrm{n} / \mathrm{a}$ & 3.5 & 210 & 130 & $\mathrm{n} / \mathrm{a}$ & - & - & + & $\mathrm{n} / \mathrm{a}$ \\
\hline MCS3 & 12 & 3.4 & 210 & 100 & - & - & - & $\mathrm{n} / \mathrm{a}$ & + & 3.2 & 210 & 100 & - & - & - & $\mathrm{n} / \mathrm{a}$ & + \\
\hline MCS4 & 6 & OFF & $\mathrm{n} / \mathrm{a}$ & $\mathrm{n} / \mathrm{a}$ & $\mathrm{n} / \mathrm{a}$ & $\mathrm{n} / \mathrm{a}$ & $\mathrm{n} / \mathrm{a}$ & $\mathrm{n} / \mathrm{a}$ & $\mathrm{n} / \mathrm{a}$ & OFF & $\mathrm{n} / \mathrm{a}$ & $\mathrm{n} / \mathrm{a}$ & $\mathrm{n} / \mathrm{a}$ & $\mathrm{n} / \mathrm{a}$ & $\mathrm{n} / \mathrm{a}$ & $\mathrm{n} / \mathrm{a}$ & $\mathrm{n} / \mathrm{a}$ \\
\hline
\end{tabular}

$\mathrm{n} / \mathrm{a}=$ not applicable; $-=$ cathode $+=$ anode $;-=$ no electrode was implanted on this particular side for this patient.

*A new implantation 12 mo after the first surgery.

that it is known that, with transcranial motor stimulation, anodal stimulation will generate $\mathrm{D}$-waves and motor evoked potentials at a lower intensity than with cathodal stimulation. ${ }^{69}$ Due to the design of the present implantable stimulators, however, options are limited to cathodal stimulation only. Also, and more importantly, work by Hanajima et al..$^{70}$ found that cathodal chronic stimulation activated neurons in the motor cortex at levels lower than did anodal stimulation. If minimal benefit was noted at later sessions, more contacts were added to the monopolar configuration. If this situation failed, then one contact (either contact 0 or contact 3 ) was placed in the cathodal mode and the other three contacts were set as the anode. Other changes that were investigated when stimulation either did not work, or started to lose efficacy, included changing the pulse width to $410 \mu \mathrm{s}$, increasing the amplitude to $4.0 \mathrm{~V}$, or changing the frequency to either 185 $\mathrm{Hz}$ or $80 \mathrm{~Hz}$. Table 1 shows the stimulation parameters relative to the surgical implant date.

In mixed poststroke patients or pure pain patients, programming was basically similar during the initial phase. Patient programming is typically begun, again, within $24 \mathrm{~h}$ of electrode implantation. At the initial programming session, all contacts are checked in a monopolar setting using $210 \mu \mathrm{s}$ and $130 \mathrm{~Hz}$. The voltage is slowly raised to $4.0 \mathrm{~V}$ while the patient is monitored for adverse motor movements and sensory changes. As amplitude is slowly increased, the patient state is evaluated. For upper limb pain care is taken to note the location of the electrode contacts intraoperatively that are over the painful area as determined by motor mapping. The electrode configuration is designed to use the contact that is centered over the area of highest motor response at the lowest stimulation level found intraoperatively. Stimulation amplitudes are started at $2.5 \mathrm{~V}$, but in some cases have gone up to $>4.0 \mathrm{~V}$. Pulse widths are started at 210 $\mu \mathrm{s}$, but in most cases in which changes were needed they have been dropped to $90 \mu \mathrm{s}$. In patients for whom MCS for pain seems to have benefit, the frequency has been kept at $130 \mathrm{~Hz}$, but in other cases a variety of frequencies are tried.

\section{Modeling technique}

To understand what effect MCS may be having on both the overall motor system and on processing of pain in general, we have performed studies in computational modeling. The software (UNCuS) for this approach was created and refined by one of the authors [J.E.A.] and is described elsewhere. ${ }^{71,72}$ It allows us to simulate general biophysics of each neuron on a conductance level, connect thousands of such independent cells together, each with electrotonic dendritic processing, and keep track of each synaptic event and time step on a $0.25 \mathrm{~ms}$ timescale.

We created a basal ganglia model to study DBS effects on the subthalamic nucleus (STN) ${ }^{73}$ and have now used this to study the effects of cortical stimulation on movement disorders. In the STN DBS model, we had a very simplified cortical representation. In studies on the mechanisms of MCS for pain syndromes, we created a more sophisticated cortical model that includes intrinsic sixlayer cortical anatomic connectivity, and used this in a separate model to examine cortico-cortical and corticothalamic processing, to explore how pain sensation within S1 may be affected by M1 stimulation.

The circuitry representing cortex is shown by the schematic in Figure 3. Anatomical findings to support these connections in appropriate ratios and synaptic configurations are found in the work of several groups. ${ }^{74-79}$ Although either more or less complexity within cortical regions can be either supported or criticized, we tried to account for a representation of the majority if not all of the major known connections and ratios. In addition, it was necessary to use subthreshold levels of stimulation in cortex. This is determined clinically by trying to see driving of motor units on EMG with $10 \mathrm{~Hz}$ stimuli.

We used a similar thresholding to determine the appropriate level of MCS in the model by using the amplitude of stimulation in the electrodes that would change the firing rate in $<50 \%$ of the cortical cells. Although many of these cells were closer to their baseline thresholds than without stimulation, they were not altered significantly in their baseline firing rates by the stimulation alone. However, and perhaps more importantly, it is 


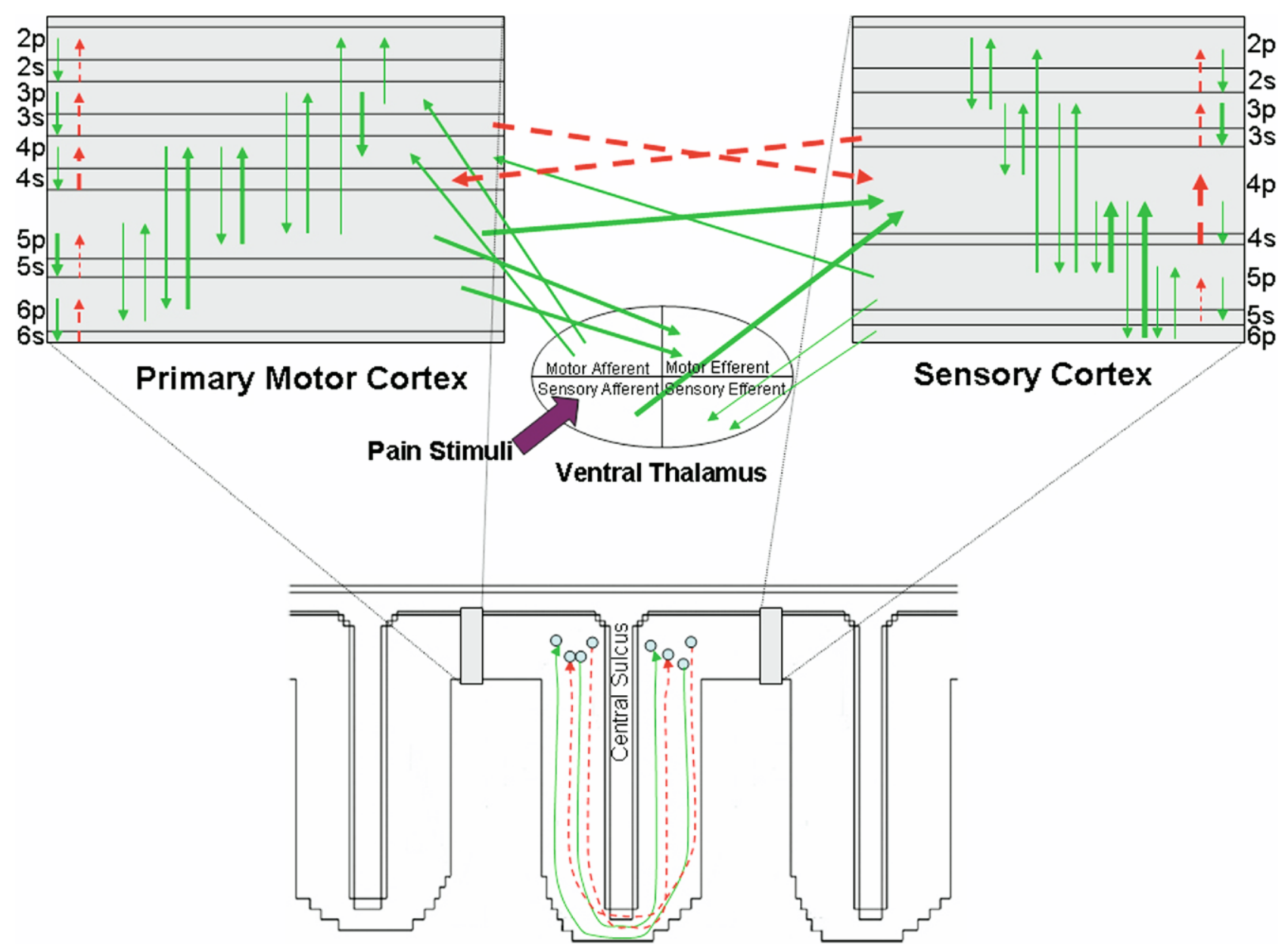

FIG. 3. Schematic showing all of the interconnections of two regions of cortex simulated using the UNCuS software program ${ }^{71,72}$ and regions of sensory and motor thalamus used to model pain processing and the effect of motor cortex stimulation (MCS) on S1. Arrows in red indicate inhibitory synapses on their targets; those in green, excitatory. All six layers are represented in M1 and S1, but have slightly different ratios of connectivities, based on supporting literature. The rendering at bottom shows the regions of cortex intended to be represented: essentially a core of the surface of the gyrus of M1 and S1. Interconnections between M1 and S1 are intended to be predominantly the $U$ fibers and are also shown in the lower diagram.

likely that surface stimulation fields from a typical paddle-type lead are affecting horizontally oriented fibers, ${ }^{80}$ rather than affecting vertically oriented fibers exiting the cortex. Many of the horizontal fibers are from the stellate category of interneurons within cortical layers 1,2 , and 3 , and these are predominantly inhibitory in nature. ${ }^{81}$ Moreover, the Toronto group ${ }^{70}$ has found that typical renderings of MCS stimulate both types of fibers, rather than directly hyperpolarizing them, as has been at times speculated. Combining these observations led us to apply MCS in the model-at subthreshold levels for motor unit driving - only to the stellate interneurons of M1 and not to the pyramidal cells (FIG. 3), which are excitatory and are more likely to be output cells from the cortex overall.

\section{RESULTS}

\section{Clinical}

Overall, we have operated on 15 patients using MCS as a treatment (Table 2). Specifically in the PD group of four patients, there was one infection 3 months after implantation and one intraoperative seizure that was generated during motor mapping. There were no other complications from the device, the implant procedure, or postoperative programming of the device. One patient developed a superficial infection of the extension wire site and required removal of the device. He had improvement of $\sim 50 \%$ over baseline in dyskinesias, but regressed significantly when the device was removed (this was the unilaterally implanted patient). After reimplantation of the device several months later, he again improved over preoperative baseline by nearly $50 \%$ again.

Two patients had a 20-30\% (M2 and M3) reduction in medication requirements at 3 months, but patient M3 started to need more medication at the 6- and 12-month time points. One patient (M5), however, had a $37 \%$ increased medication requirement. One patient had a return of dyskinesias after 3 months (M5); this patient had initially improved, but then the amplitude of stimulation 
TABLE 2. Our Series of MCS Patients

\begin{tabular}{llccl}
\hline Patient ID & Diagnosis & $\begin{array}{c}\text { Time Since } \\
\text { Surgery, } \\
\text { mo }\end{array}$ & $\begin{array}{c}\text { Age, } \\
\text { years }\end{array}$ & Outcome \\
\hline P1 & PSM & 39 & 64 & Fair \\
M1 & ET & 36 & 56 & Poor \\
P2 & PSM & 36 & 61 & Good \\
P3 & NPSP & 35 & 41 & Fair \\
P4 & PSM & 34 & 64 & Fair \\
P5 & PSP & 30 & 58 & Good \\
M2 & PD & 27 & 73 & Fair to \\
& & & & Poor \\
P6 & PSM & 23 & 49 & Poor \\
M3 & PD & 21 & 67 & Fair to \\
& & & & Poor \\
M4 & ET & 21 & 89 & Poor \\
M5 & PD & 20 & 45 & Good to \\
& & & & Fair \\
P7 & PSP & 17 & 64 & Poor \\
M6 & PD & 16 & 66 & Fair \\
M7 & CBD & 17 & 62 & Poor \\
P8 & CRP & 1 & 45 & - \\
Mean & & 25 & 60 & \\
Std Dev & & 10 & 12 & \\
Max & & 39 & 89 & \\
Min & & 1 & 41 & \\
\hline
\end{tabular}

$\mathrm{CBD}=$ cortico-basal degeneration; $\mathrm{CRP}=$ complex regional pain; $\mathrm{ET}=$ essential tremor; NPSP $=$ non-poststroke pain; $\mathrm{PD}=$ Parkinson's disease; PSM = poststroke mixed pain-movement disorders; PSP $=$ poststroke pain.

*As of the time of this report.

was reduced and the benefit was lost. Once the stimulation amplitude was increased again, the patient's dyskinesias were again better controlled.

We examined scores for UPDRS Part III (motor dis- ability) over the initial 12 months of the study (FIG. 4; Table 3). Although significant benefit in these motor scores can be discerned within the initial 6 months, the trend was returning to baseline by 12 months, suggesting that there is only a transient benefit with MCS, at least using parameters described herein. Tables 3 and 4 show how the UPDRS total scores changed over time in the ON medication-ON stimulation state for the UPDRS part III scores and the total UPDRS. Table 5 shows the changes in medication over the study period.

In our series of pain patients, results are even less consistent. With the eight patients for whom pain played a prominent role, five cases were poststroke pain, one was atypical head pain due to a traumatic fall (this patient failed both spinal and peripheral nerve stimulation), one was atypical head pain, and one was due to complex regional pain syndrome secondary to a brachial plexus avulsion most likely (this patient had failed both a spinal cord and peripheral nerve stimulator).

Of the five poststroke pain patients, three cases were mixed pain and movement disorders. One of those three (P7) received no benefit from the stimulation for either the pain or the movement disorder. The other two (P4 and P5) received varying degrees of benefit. Patient P5 has good control of pain in her upper extremities and face, with less pain control in her leg region and minimal control of a third-limb sensation. Patient P4 has fair control of her pain and fair control of an internal tremor. The patient with atypical head pain due to a fall has had no benefit from the MCS for pain in his contralateral scalp, but is getting benefit in his ipsilateral scalp, curiously.

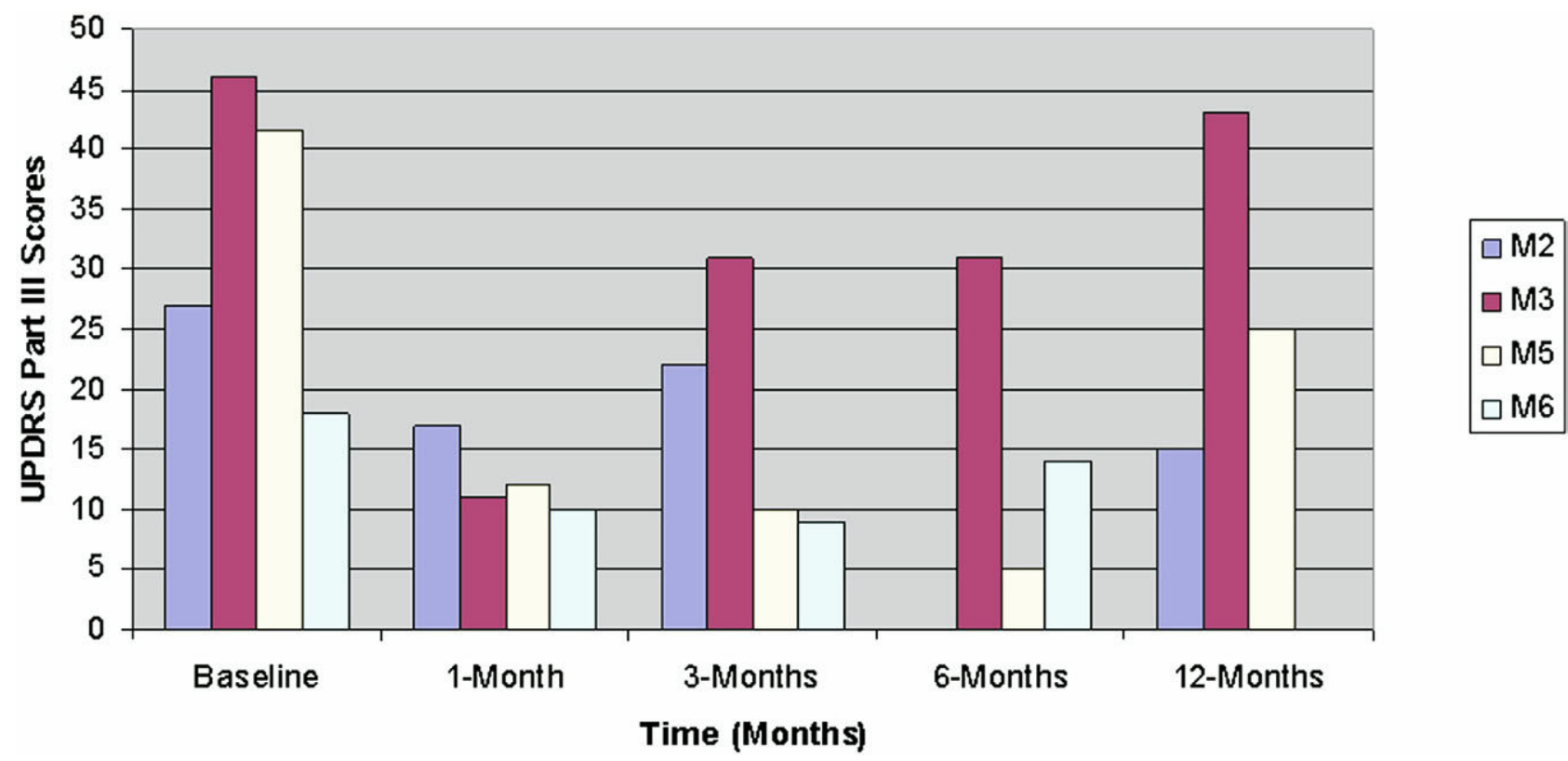

FIG. 4. UPDRS part III (on stimulation, off medication) over the initial 12 months in four patients with Parkinson's disease. Averaging at each time point shows that benefit was seen over the first 6 months, but then returned nearly to baseline by 12 months. 
TABLE 3. UPDRS Part III (Motor) Scores During ON Medication and ON Stimulation

\begin{tabular}{lllcccc}
\hline & \multicolumn{7}{c}{ UPDRS III Score } \\
\cline { 2 - 7 } Patient & Pre & $1 \mathrm{mo}$ & $3 \mathrm{mo}$ & $6 \mathrm{mo}$ & $1 \mathrm{yr}$ & New 6 \\
& ON & ON & ON & ON & ON & mo ON \\
\hline MCS1 & 19 & 26 & 25 & (Inf.) & (Inf.) & 23 \\
MCS2 & 32 & 47 & 13 & 18 & 35 & - \\
MCS3 & 24.5 & 12 & 18 & OFF & - & - \\
MCS4 & 11 & - & OFF & OFF &
\end{tabular}

Inf. $=$ infection.

Programming of our pain patients includes a wide range of stimulation parameters with voltage varying from $2.2 \mathrm{~V}$ up to $4.2 \mathrm{~V}$, pulse width varying from $120 \mu \mathrm{s}$ up to $330 \mu \mathrm{s}$, and frequency varying from $50 \mathrm{~Hz}$ up to $130 \mathrm{~Hz}$. All patients start with monopolar settings, but often bipolar settings are used with more anodal contacts.

Benefits in our other MCS patients remain mixed. Anecdotally, however, there have clearly been modest successes in our hands. Recently, for example, we have had three patients who each called in to say they had noticed worsening of their symptoms over the previous month or so and that maybe they needed reprogramming: one patient with PD (M5) and two with poststroke upper extremity pain (P5) or mixed (P1). At the programming visit, it was found that each of them had completely depleted the implantable pulse generator batteries; all three regained the previous benefit level after the batteries were replaced. None had a hand controller device to check battery levels, nor had they been seen in the clinic recently, where their batteries might have been checked and noted to be waning.

\section{Modeling}

Significant findings in our original modeling of STN DBS included appreciating that DBS had effects on globus pallidus pars interna (GPi) and thalamic cells only at frequencies of $>130 \mathrm{~Hz}$ (the level at which therapeutic effects are seen), that subsequent variance of firing in GPi and thalamus was more notable than average firing rate changes, and that power spectral changes in the thalamic tremor frequency range were significantly diminished with STN DBS. ${ }^{73}$ Changes in the GPi with
MCS in the model, in terms of firing rate and variance of the interspike interval, are shown in Figure 5. Note that both STN DBS and MCS significantly alter the variance in GPi cells. Such changes were unexpected, but were found in our STN DBS modeling ${ }^{73}$ and are also found within the same basal ganglia model using MCS.

A more sophisticated model of the cortical anatomy and physiology was used in a thalamo-cortical circuit, to explore how pain signaling might be affected by MCS subthreshold stimulation. Because only the interneurons, the majority of which are inhibitory, had MCS applied, it is likely that this region of M1 would exhibit a general decrease in firing rate and, by definition, would not reveal motor unit driving by EMG. Figure 6 shows how topographically arrayed synaptic input from sensory thalamus of an $80-\mathrm{Hz}$ regional stimulation (graphically shown by cumulative activity; FIG. 6a) to the receiving layer 4 pyramidal cells of S1 would also lead to decreased activity in these layer 4 pyramidal cells overall (FIG. 7). Likely this is related to the $\mathrm{U}$ fiber (subcortical arcuate fasiculi) excitation from M1 being inhibited locally by stimulation of the horizontally oriented axons of the associative inhibitory cells. The lack of even baseline excitation from M1 layer 5 pyramidal cells, which send output to layer 4 pyramidal cells in S1, would create a lower firing rate in those targets. Figure $6 \mathrm{~b}$ shows the cumulative change in firing rate graphed to reveal location within this cortical region. Note that there is a convergence and focus of activity going from sensory thalamus (FIG. 6a) to S1 pyramidal cells (FIG. 6b). The significant change in activity is centered only within the

TABLE 4. UPDRS Total Scores During ON Medication and ON Stimulation

\begin{tabular}{lllccccc}
\hline & \multicolumn{7}{c}{ UPDRS Total Score } \\
\cline { 2 - 7 } Patient & Pre & Pre & 1 mo & 3 mo & 6 mo & 1 yr & New 6 \\
mo ON
\end{tabular}

Inf. = infection. 
TABLE 5. Levodopa Daily Milliequivalents

Daily Levodopa Milliequivalents

\begin{tabular}{|c|c|c|c|c|c|c|}
\hline Patient & Pre & $1 \mathrm{mo}$ & $3 \mathrm{mo}$ & $6 \mathrm{mo}$ & $1 \mathrm{yr}$ & $\begin{array}{l}\text { New } \\
6 \text { mo }\end{array}$ \\
\hline MCS1 & 2140 & 2140 & 1874 & (Inf.) & pre 1044 ; post 1320 & 1520 \\
\hline MCS2 & 1204 & 754 & 654 & 1054 & 1054 & - \\
\hline MCS3 & 820 & 850 & 1000 & 910 & 950 & - \\
\hline MCS4 & 1090 & 1320 & 1090 & 1090 & - & - \\
\hline
\end{tabular}

Inf. $=$ infection; pre $=$ pre new implant; post $=$ post new implant.

topographically oriented region which was coding for the painful stimulus coming from sensory thalamus.

\section{DISCUSSION}

Electrical interface with the nervous system has become commonplace in recent years. Stimulation of the cortex, in particular, has been tried for treating refractory pain syndromes, especially in the upper extremity and face, and for treating a variety of movement disorders including PD, tremor, and poststroke dystonias.

It is important to compare MCS with DBS, even at this early stage of development. DBS has become a standard approach in treating patients with $\mathrm{PD}$ who have become more or less refractory to further medical management. However, many patients would be more comfortable with DBS as an option, and many more neurologists would be more comfortable referring patients for sur- gery, if the risk of an intracerebral hemorrhage were eliminated. This complication is rare by most accounts. Our program has had no significant hemorrhages, and one questionable minor hemorrhage, in 200 implants, and most reported series suggest the risk is $<2 \%$, with a range of $0.2 \%$ to $9.5 \% .^{82}$

MCS offers the possibility of a surgical option without this risk. Moreover, the need to perform surgery awake in these patients, typically with microelectrode recording and macro stimulation, is also unnecessary with MCS. If MCS is as effective as DBS in treating the cardinal symptoms of PD, and shows itself to have equal or fewer complications, or more comfort for the patient overall, then it becomes a preferable option for this category of patient.

Despite several reports suggesting that MCS is beneficial in $\mathrm{PD},{ }^{60}$ our results are consistent with these findings only within the first 12 months. More detailed anal-

GPi Regularity with Cortical Stimulation

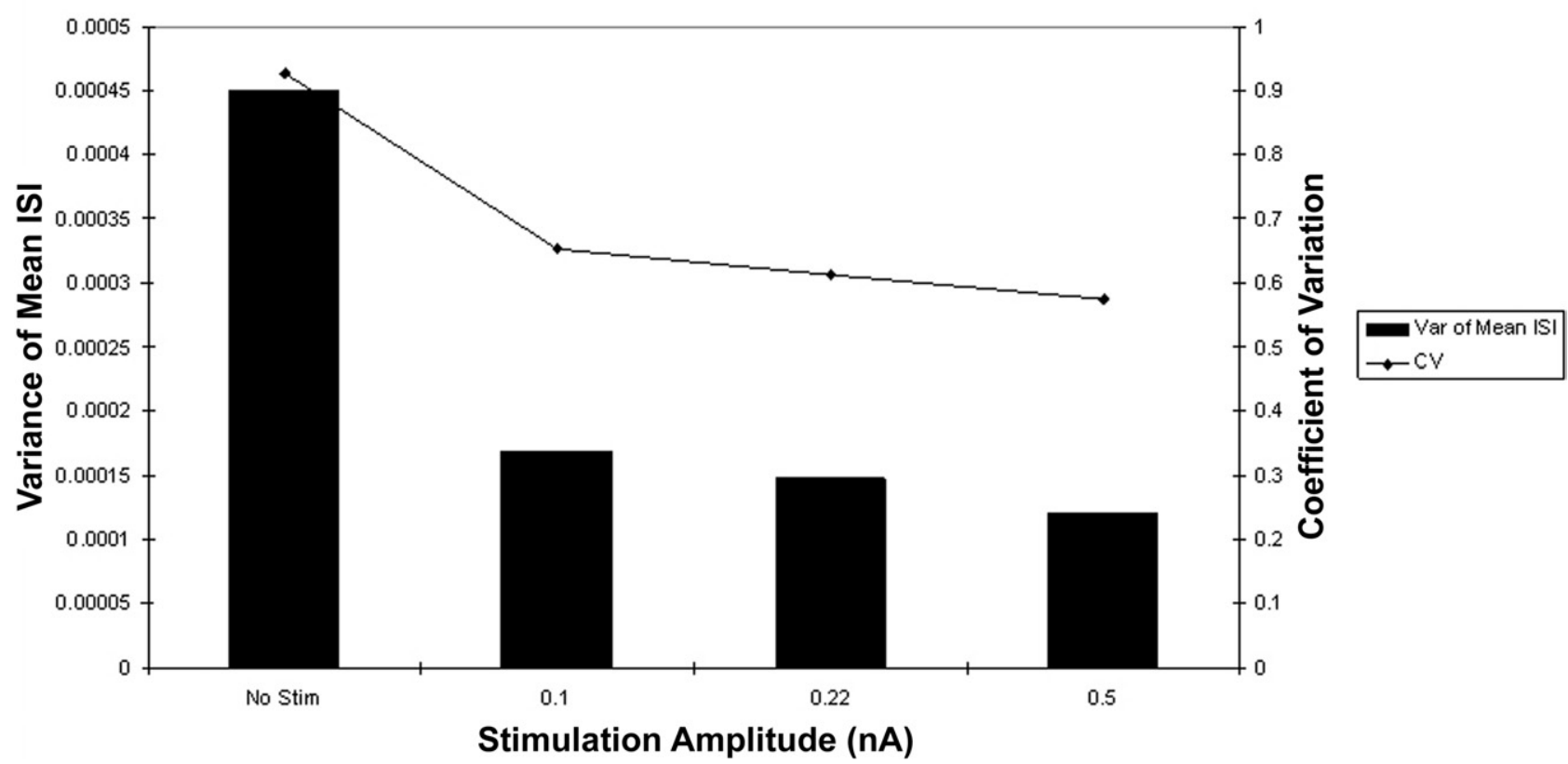

FIG. 5. Variance (Var) and coefficient of variation (CV) of the interspike interval (ISI) within the globus pallidus pars interna (GPi) region of our basal ganglia model with MCS at increasing amplitudes. The variance decreases significantly. This is similar to what we had found previously with stimulation of the subthalamic nucleus in the same model. 
Neuronal Activity

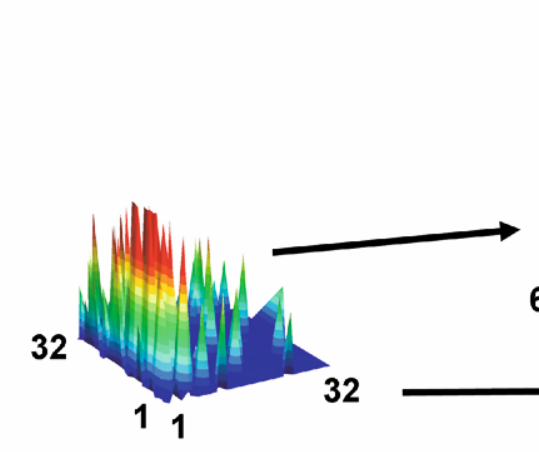

Afferent Sensory Thalamus

A

FIG. 6. (A) Cumulative activity over $20 \mathrm{~s}$ of simulated time with a pulsatile $80-\mathrm{Hz}$ stimulus in a discrete region of the topographically oriented sensory thalamus. The peak activity over time (in red) represents the activity coming from this area and coding for a more specific region of the body. The cells synapse directly on layer 4 pyramidal cells in the S1 representation of the model (FIG. 3). (B) Cumulative activity difference before and after MCS in the model. Note that MCS inhibits the activity level only in the discrete region of $\mathrm{S} 1$ that would represent coding for the same specific body region, topographically driving it from the sensory thalamus.

ysis of these earlier studies suggests that patients often benefited early on and then lost those gains over time. One other preliminary study, ${ }^{83}$ using subdural electrode placement, found benefit only in tremor scores for one tremor-predominant patient. Akinesia, rigidity, and gait demonstrated no improvement with MCS. Altogether, these studies involved $\sim 27$ patients (counting up the patients from the Italian groups, ${ }^{60}$ the Canavero team, ${ }^{55}$ the one limited Toronto study, ${ }^{83}$ and our own patients). Controversy still remains as to whether the best electrode location is parallel or perpendicular to M1, extradural or subdural, what parameters should be used for programming postoperatively, what stimulation polarity has importance, and whether results, if any, are immediate or should be looked for only after weeks to months.

An important question relating to MCS is, what elements of the motor cortex are being stimulated? Are the cortico-spinal fibers being stimulated directly, as occurs with transcortical motor evoked potentials, or are we stimulating something else? Animal studies by Drouot et al. ${ }^{56}$ demonstrate a renormalization of both STN and GPi firing rates after motor cortical stimulation in monkeys lesioned with 1-methyl-4-phenyl-1,2,3,6-tetrahydropyridine (MPTP). The stimulation paradigm they used was similar to ours in that they were stimulating with two cathodal leads. An important finding in their study was that the effect of MCS on STN and GPi firing rates was almost immediate, whereas the clinical changes can take from minutes to days to reveal themselves.

Our modeling efforts to date suggest that MCS may have influence on the basal ganglia similar to that of STN DBS. It may be, however, that most of the effects of MCS in movement disorders are from mediation with outflow of the
M1 region to spinal cord circuitry. Moreover, whatever effect it is having wanes over several months if parameter settings are kept constant, suggesting that perhaps longerterm changes eventually catch up within the circuitry (e.g., DNA and protein processes) to limit the effectiveness of MCS. We have not modeled such changes explicitly, but plan to explore these ideas in the future.

The delay in the time scale of clinical efficacy of MCS, on the order of months, has been suggested by others in this context. Specifically, Drouot et al.$^{56}$ mention the possibilities of secondary messengers or longterm potentiation as possible reasons for this time difference. One speculation is that chronic MCS may alter not only the firing patterns in the basal ganglia but also, due to its location, the interactions between the pyramidal and extrapyramidal systems. This then raises the question of how long it may take for both the thalamocortico-basal ganglia loops and the cortico-cortical loops to equilibrate to the new signal patterns.

With respect to the modification of pain by MCS, our representation of a painful stimulus arising through sensory thalamic cells and carried on to S1 is then inhibited by MCS acting on just the inhibitory interneurons of M1. This finding in the model is supported by data demonstrating that the M1 and S1 regions are inhibited by MCS (albeit likely at higher amplitudes). ${ }^{70,84,85}$ In contrast, MCS excites both outgoing pyramidal cells and inhibitory interneurons. ${ }^{70,84}$ One hypothesis from this line of thought is that subthreshold amplitudes of MCS excite only the horizontal inhibitory fibers, whereas higher amplitudes of MCS also stimulate excitatory layer 5 pyramidal cells (for instance) in M1 in addition to the inhibitory interneurons and this increased activity would override the inhibition and lead to motor unit 

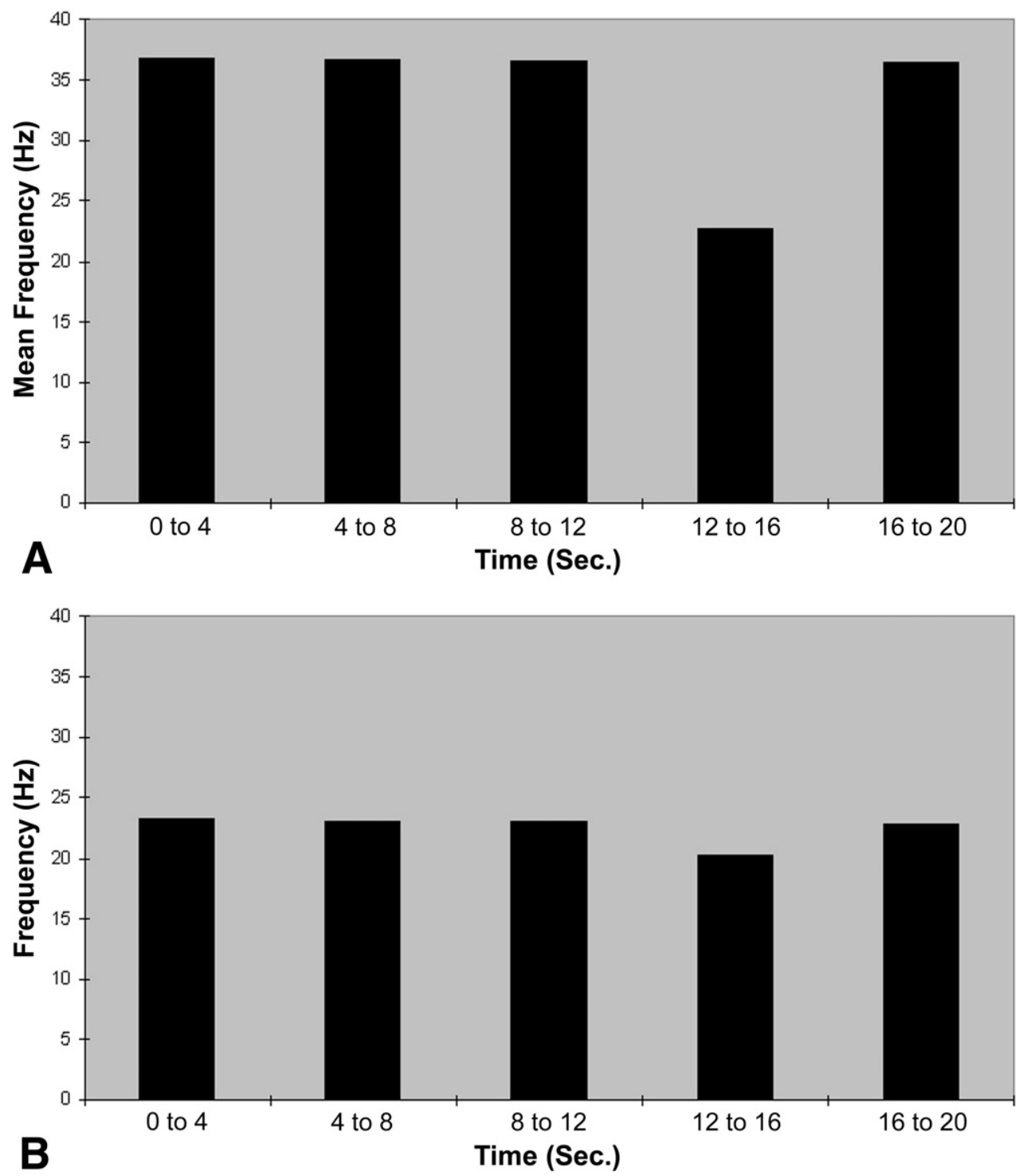

FIG. 7. Mean firing rates in the $\mathrm{S} 1$ cell population in the model, over $20 \mathrm{~s}$ of simulated time, for topographically active (A) and nonactive (B) pain area in S1. MCS is activated only between 12 and $16 \mathrm{~s}$ and is off the rest of the time; the decrease in overall firing rate during this time is significant (panel a). In the absence of stimulation (panel b), there is no change in S1 activity throughout the entire simulation.

driving, which indeed does occur clinically (personal observation). It remains to be validated whether MCS drives predominantly inhibitory fibers coursing horizontally within the exposed parts of the M1 gyrus, and these in turn lead to local inhibition and then subsequent lack of layer 5 excitation of S1 (thus inhibiting S1 by providing less excitation as well), but our model does support this possibility.

In reviewing MCS results from both the pain and movement disorder literature, it remains unclear whether MCS represents a major advance as a treatment option or has limitations that await further refinement. Our experience, although limited, suggests that in certain cases, there is longer lasting benefit, at least over 12-24 months, clinically. Deciding which patients may or may not have long-term benefit from MCS may prove to be exceedingly difficult. Moreover, because the procedure has a very low frequency side-effect profile, below that of even DBS, it will likely be tried in many cases anyway, after other methods of treatment have failed. Determining the cause of benefit or failure in patients with MCS may then depend on electrode location, programming parameters, patient selection, or some combination of all three, varying from case to case. Further work may succeed in providing answers to these questions.

Acknowledgments: We wish to acknowledge funding from the Sydney Family, the Robert E. Wise Research Foundation, Mort Goulder, MBA, and Manny Landsmann, PhD. Also, we wish to thank Dr. Diana Apetauerova, MD, for clinical expertise in movement disorders. 


\section{REFERENCES}

1. Gabriel EM, Nashold BS Jr. Evolution of neuroablative surgery for involuntary movement disorders: an historical review. Neurosurgery 1998;42:575-590.

2. Vilensky JA, Gilman S. Using extirpations to understand the human motor cortex: Horsley, Foerster, and Bucy. Arch Neurol 2003; 60:446-451.

3. Mundinger F. New stereotactic treatment of spasmodic torticollis with a brain stimulation system [In German]. Med Klin 1977;72: 1982-1986.

4. Siegfried J. Deep brain stimulation for movement disorders. In: Gildenberg PL, Tasker RR, editors. A textbook of stereotactic and functional neurosurgery. Philadelphia: McGraw-Hill; 1996:10811086.

5. Lende RA, Kirsch WM, Druckman R. Relief of facial pain after combined removal of precentral and postcentral cortex. J Neurosurg 1971;34:537-543.

6. White JC, Sweet WH. Pain: its mechanisms and neurosurgical control. Springfield, IL: Charles C. Thomas, 1955.

7. Heath RG. Psychiatry. Annu Rev Med 1954;5:223-236.

8. Woolsey CN, Erickson TC, Gilson WE. Localization in somatic sensory and motor areas of human cerebral cortex as determined by direct recording of evoked potentials and electrical stimulation. Neurosurgery 1979;51:476-506.

9. Hosobuchi Y. Subcortical electrical stimulation for control of intractable pain in humans: report of 122 cases (1970-1984). J Neurosurg 1986;64:543-553.

10. Tsubokawa T, Katayama Y, Yamamoto T, Hirayama T, Koyama S. Chronic motor cortex stimulation for the treatment of central pain. Acta Neurochir Suppl (Wien) 1991;52:137-139.

11. Tsubokawa T. Chronic stimulation of deep brain structures for treatment of chronic pain. In: Tasker RR, editor. Neurosurgery: state of the art reviews, vol 2. Stereotactic surgery. Philadelphia: Hanley \& Belfus, 1987:253-255.

12. Nguyen JP, Pollin B, Fève A, Geny C, Cesaro P. Improvement of action tremor by chronic cortical stimulation. Mov Disord 1998; 13:84-88.

13. Brown JA, Lutsep HL, Weinand M, Cramer SC. Motor cortex stimulation for the enhancement of recovery from stroke: a prospective, multicenter safety study. Neurosurgery 2006;58: 464-473.

14. Canavero S, Bonicalzi V, Castellano G, Perozzo P, Massa-Micon B. Painful supernumerary phantom arm following motor cortex stimulation for central poststroke pain. J Neurosurg 1999;91:121123.

15. Canavero S, Bonicalzi V. Therapeutic extradural cortical stimulation for central and neuropathic pain: a review [Erratum in: Clin $\mathrm{J}$ Pain 2002;18:195]. Clin J Pain 2002;18:48-55.

16. Carroll D, Joint C, Maartens N, Shlugman D, Stein J, Aziz TZ. Motor cortex stimulation for chronic neuropathic pain: a preliminary study of 10 cases. Pain 2000;84:431-437.

17. Ebel H, Rust D, Tronnier V, Böker D, Kunze S. Chronic precentral stimulation in trigeminal neuropathic pain. Acta Neurochir (Wien) 1996;138:1300-1306.

18. Franzini A, Ferroli P, Servello D, Broggi G. Reversal of thalamic hand syndrome by long-term motor cortex stimulation. J Neurosurg 2000;93:873-875.

19. Fujii M, Ohmoto Y, Kitahara T, et al. Motor cortex stimulation therapy in patients with thalamic pain [In Japanese]. No Shinkei Geka 1997;25:315-319.

20. García-Larrea L, Peyron R, Mertens P, et al. Electrical stimulation of motor cortex for pain control: a combined PET-scan and electrophysiological study. Pain 1999;83:259-273.

21. Herregodts P, Stadnik T, De Ridder F, D'Haens J. Cortical stimulation for central neuropathic pain: 3-D surface MRI for easy determination of the motor cortex. Acta Neurochir Suppl (Wien) 1995;64:132-135.

22. Hosobuchi Y. Motor cortex stimulation for control of central deafferentation pain. In: Devinsky O, Berić A, Dogali M, editors. Electrical and magnetic stimulation of the brain and spinal cord. New York, Raven Press, 1993:215-217.
23. Katayama Y, Tsubokawa T, Yamamoto T. Chronic motor cortex stimulation for central deafferentation pain: experience with bulbar pain secondary to Wallenberg syndrome. Stereotact Funct Neurosurg 1994;62:295-299.

24. Katayama Y, Fukaya C, Yamamoto T. Control of poststroke involuntary and voluntary movement disorders with deep brain or epidural cortical stimulation. Stereotact Funct Neurosurg 1997;69: $73-79$.

25. Katayama Y, Fukaya C, Yamamoto T. Poststroke pain control by chronic motor cortex stimulation: neurological characteristics predicting a favorable response. J Neurosurg 1998;89:585-591.

26. Katayama Y, Oshima H, Fukaya C, Kawamata T, Yamamoto T. Control of post-stroke movement disorders using chronic motor cortex stimulation. Acta Neurochir Suppl (Wien) 2001;79:89-92.

27. Katayama Y, Yamamoto T, Kobayashi K, Kasai M, Oshima H, Fukaya C. Motor cortex stimulation for phantom limb pain: a comprehensive therapy with spinal cord and thalamic stimulation. Stereotact Funct Neurosurg 2001;77:159-162.

28. Mertens P, Nuti C, Sindou M, et al. Precentral cortex stimulation for the treatment of central neuropathic pain: results of a prospective study in a 20-patient series. Stereotact Funct Neurosurg 1999; $73: 122-125$.

29. Meyerson BA, Lindblom U, Linderoth B, Lind G, Herregodts P. Motor cortex stimulation as treatment of trigeminal neuropathic pain. Acta Neurochir Suppl (Wien) 1993;58:150-153.

30. Migita K, Uozumi T, Arita K, Monden S. Transcranial magnetic coil stimulation in patients with central pain. Neurosurgery 1995; 36:1037-1039.

31. Mogilner AY, Rezai AR. Epidural motor cortex stimulation with functional imaging guidance? Neurosurg Focus 2001;11(3):E4.

32. Nguyen JP, Lefaucheur JP, Decq P, et al. Chronic motor cortex stimulation in the treatment of central and neuropathic pain: correlations between clinical, electrophysiological and anatomical data. Pain 1999; 82:245-251.

33. Pagni CA, Zeme S, Zenga F, Maina R. Extradural motor cortex stimulation in advanced Parkinson's disease: the Turin experience: technical case report. Neurosurgery 2005;57(4 Suppl):E402; discussion E402.

34. Pirotte B, Voordecker P, Joffroy F, et al. The Zeiss-MKM system for frameless image-guided approach in epidural motor cortex stimulation for central neuropathic pain. Neurosurg Focus 2001; 11(3):E3.

35. Rainov NG, Fels C, Heidecke V, Burkert W. Epidural electrical stimulation of the motor cortex in patients with facial neuralgia. Clin Neurol Neurosurg 1997;99:205-209.

36. Rainov NG, Heidecke V. Motor cortex stimulation for neuropathic facial pain. Neurol Res 2003;25:157-161.

37. Roux FE, Ibarrola D, Tremoulet M, et al. Methodological and technical issues for integrating functional magnetic resonance imaging data in a neuronavigation system. Neurosurgery 2001;49: $1145-1156$.

38. Saitoh Y, Shibata M, Sanada Y, Mashimo T. Motor cortex stimulation for phantom limb pain. Lancet 1999;353:212.

39. Saitoh Y, Shibata M, Hirano S, Hirata M, Mashimo T, Yoshimine $\mathrm{T}$. Motor cortex stimulation for central and peripheral deafferentation pain: report of eight cases. J Neurosurg 2000;92:150-155.

40. Saitoh Y, Hirano S, Kato A, et al. Motor cortex stimulation for deafferentation pain. Neurosurg Focus 2001;11(3):E1.

41. Saitoh Y, Kato A, Ninomiya H, et al. Primary motor cortex stimulation within the central sulcus for treating deafferentation pain. Acta Neurochir Suppl (Wien) 2003;87:149-152.

42. Smith H, Joint C, Schlugman D, Nandi D, Stein JF, Aziz TZ. Motor cortex stimulation for neuropathic pain. Neurosurg Focus 2001;11(3):E2.

43. Son UC, Kim MC, Moon DE, Kang JK. Motor cortex stimulation in a patient with intractable complex regional pain syndrome type II with hemibody involvement: case report. J Neurosurg 2003;98: 175-179.

44. Sol JC, Casaux J, Roux FE, et al. Chronic motor cortex stimulation for phantom limb pain: correlations between pain relief and functional imaging studies. Stereotact Funct Neurosurg 2001;77:172176. 
45. Tsubokawa T, Katayama Y, Yamamoto T, Hirayama T, Koyama S. Chronic motor cortex stimulation in patients with thalamic pain. J Neurosurg 1993;78:393-401.

46. Velasco M, Velasco F, Brito F, et al. Motor cortex stimulation in the treatment of deafferentation pain: I. Localization of the motor cortex. Stereotact Funct Neurosurg 2002;79:146-167.

47. Tani N, Saitoh Y, Hirata M, Kato A, Yoshimine T. Bilateral cortical stimulation for deafferentation pain after spinal cord injury: case report. J Neurosurg 2004;101:687-689.

48. Nuti C, Peyron R, García-Larrea L, et al. Motor cortex stimulation for refractory neuropathic pain: four year outcome and predictors of efficacy. Pain 2005;118:43-52.

49. Rasche D, Ruppolt M, Stippich C, Unterberg A, Tronnier VM. Motor cortex stimulation for long-term relief of chronic neuropathic pain: a 10 year experience. Pain 2006;121:43-52.

50. Peyron R, Faillenot I, Mertens P, Laurent B, García-Larrea L. Motor cortex stimulation in neuropathic pain: correlations between analgesic effect and hemodynamic changes in the brain: a PET study. Neuroimage 2007;34:310-321.

51. Brown JA, Pilitsis JG. Motor cortex stimulation for central and neuropathic facial pain: a prospective study of 10 patients and observations of enhanced sensory and motor function during stimulation. Neurosurgery 2005;56:290-297.

52. Kishima H, Saitoh Y, Osaki Y, et al. Motor cortex stimulation in patients with deafferentation pain activation of the posterior insula and thalamus. J Neurosurg 2007;107:43-48.

53. Brown JA, Lutsep H, Cramer SC, Weinand M. Motor cortex stimulation for enhancement of recovery after stroke: case report. Neurol Res 2003;25:815-818.

54. Canavero S, Paolotti R, Bonicalzi V, et al. Extradural motor cortex stimulation for advanced Parkinson disease: report of two cases. J Neurosurg 2002;97:1208-1211.

55. Canavero S, Bonicalzi V, Paolotti R, et al. Therapeutic extradural cortical stimulation for movement disorders: a review. Neurol Res 2003;25:118-122.

56. Drouot X, Oshino S, Jarraya B, et al. Functional recovery in a primate model of Parkinson's disease following motor cortex stimulation. Neuron 2004;44:769-778.

57. Franzini A, Ferroli P, Dones I, Marras C, Broggi G. Chronic motor cortex stimulation for movement disorders: a promising perspective. Neurol Res 2003;25:123-126.

58. Katayama Y, Fukaya C, Yamamoto T. Control of post-stroke involuntary and voluntary movement disorders with deep brain or epidural cortical stimulation. Stereotact Funct Neurosurg 1997;69: 73-79.

59. Kleiner-Fisman G, Fisman DN, Kahn FI, Sime E, Lozano AM, Lang AE. Motor cortical stimulation for parkinsonism in multiple system atrophy. Arch Neurol 2003;60:1554-1558.

60. Pagni C, Altibrandi MG, Bentivoglio A, et al. Extradural motor cortex stimulation (EMCS) for Parkinson's disease: history and first results by the study group of the Italian Neurosurgical Society. Acta Neurochir Suppl (Wien) 2005;93:113-119.

61. Rodríguez RF, Contreras N. Bilateral motor cortex stimulation for the relief of central dysesthetic pain and intentional tremor secondary to spinal cord surgery: a case report. Neuromodulation 2002;5:189-195.

62. Arle JE, Apetauerova D, Zani J, et al. Motor cortex stimulation for Parkinson's disease: 12 month follow-up in 4 patients. J Neurosurg (in press).

63. Cilia R, Landi A, Vergani F, Sganzerla E, Pezzoli G, Antonini A. Extradural motor cortex stimulation in Parkinson's disease. Mov Disord 2007;22:111-114.

64. Munno D, Caporale S, Zullo G, et al. Neuropsychologic assessment of patients with advanced Parkinson disease submitted to extradural motor cortex stimulation. Cogn Behav Neurol 2007;20: $1-6$.
65. Son BC, Lee SW, Choi ES, Sung JH, Hong JT. Motor cortex stimulation for central pain following a traumatic brain injury. Pain 2006;123:210-216.

66. Nguyen JP, Keravel Y, Feve A, et al. Treatment of deafferentation pain by chronic stimulation of the motor cortex: report of a series of 20 cases. Acta Neurochir Suppl (Wien) 1997;68:54-60.

67. Cioni B. Motor cortical stimulation for Parkinson's disease: The Italian Neurosurgical Study Group. Presented at: 14th World Society for Stereotactic and Functional Neurosurgery Meeting, Rome, 2005.

68. Cioni B. Motor cortical stimulation for Parkinson's disease: The Italian Neurosurgical Study Group. Presented at: 5th International Symposium on Intraoperative Neurophysiological Monitoring in Neurosurgery, New York, 2006.

69. Amassian VE, Stewart M, Quirk GJ, Rosenthal JL. Physiological basis of motor effects of a transient stimulus to cerebral cortex. Neurosurgery 1987;20:74-93.

70. Hanajima R, Ashby P, Lang AE, Lozano AM. Effects of acute stimulation through contacts placed on the motor cortex for chronic stimulation. Clin Neurophysiol 2002;113:635-641.

71. Arle JE, Mei LZ, Shils JL. Modeling parkinsonian circuitry and the DBS electrode: I. Biophysical background and software. Stereotact Funct Neurosurg 2007;86:1-15.

72. Arle JE. Neural modeling of the cochlear nucleus [dissertation] Storrs: University of Connecticut, 1992.

73. Shils JL, Mei LZ, Arle JE. Modeling parkinsonian circuitry and the DBS electrode: II. Evaluation of a computer simulation model of the basal ganglia with and without subthalamic nucleus stimulation. Stereotact Funct Neurosurg 2007;86:16-29.

74. Sloper JJ, Hiorns RW, Powell TPS. A qualitative and quantitative electron microscopic study of the neurons in the primate motor and somatic sensory cortices. Philos Trans R Soc Lond B Biol Sci 1979;285:141-171.

75. Sloper JJ. An electron microscopic study of the neurons of the primate motor and somatic sensory cortices. J Neurocytol 1973;2: 351-359.

76. Bannister AP. Inter- and intra-laminar connections of pyramidal cells in the neocortex. Neurosci Res 2005;53:95-103.

77. Porter LL. Patterns of connectivity in the cat sensory-motor cortex: a light and electron microscope analysis of the projection arising from area 3a. J Comp Neurol 1991;312:404-414.

78. Zarzecki P, Shinoda Y, Asanuma H. Projection from area 3 a to the motor cortex by neurons activated from group I muscle afferents. Exp Brain Res 1978;33:269-282.

79. Rocco MM, Brumberg JC. The sensorimotor slice. J Neurosci Methods 2007;162:139-147.

80. Manola L, Holsheimer J, Veltink P, Buitenweg JR. Anodal vs cathodal stimulation of motor cortex: a modeling study. Clin Neurophysiol 2007;118:464-474.

81. Douglas R, Martin K. Neocortex. In: Shepherd GM, editor. The synaptic organization of the brain, 4th ed. New York: Oxford University Press; 1998:459-510.

82. Alterman RL, Sterio D, Beric A, Kelly PJ. Microelectrode recording during posteroventral pallidotomy: impact on target selection and complications. Neurosurgery 1999;44:315-321.

83. Schwalb JM, Moro E, Hamani C, et al. Open label trial of subdural motor cortex stimulation (MCS) for Parkinson's disease [Abstract]. Stereotact Funct Neurosurg 2007;85:24.

84. Di Lazzaro V, Oliviero A, Pilato F, et al. The physiological basis of transcranial motor cortex stimulation in conscious humans. Clin Neurophysiol 2004;115:255-266.

85. Ikeda A, Ohara S, Matsumoto R, et al. Role of primary somatosensory cortices in generating inhibitory motor response in humans. Brain 2000;123:1710-1721. 